\title{
Anticoagulants in the treatment of small cell carcinoma of the bronchus
}

\author{
C F STANFORD
}

From the Forster Green Hospital, Belfast, Northern Ireland

\begin{abstract}
The object of this study was to see if the addition of anticoagulants to a regimen of cytotoxic drugs would improve the prognosis in patients with small cell carcinoma of the bronchus. Twenty-four patients were randomly allocated to receive chemotherapy or chemotherapy plus anticoagulants. The median survival in the group receiving the anticoagulants was not improved.
\end{abstract}

Survival rates in patients with carcinoma of the bronchus are generally poor except in that small percentage who are diagnosed when they have early lesions (Vincent et al, 1976). Patients operated on for small cell carcinoma have a particularly bad outlook, although occasional reports have shown promising results (Stanford et al, 1976). The median survival time from the date of histological diagnosis in patients with this cell type, if untreated, is under three months (Hyde et al, 1965). This adverse prognosis is probably related to the extensive metastases found in patients with small cell carcinoma of the bronchus (Takita et al, 1973).

Animal studies have shown that metastases can become established by cancer cells adhering to the capillary endothelium where they become covered by fibrin and platelets, which in turn are covered by regrowth of the endothelium (Wood, 1958). Thus an extravascular nidus of malignant cells may develop in a site less susceptible to immune mechanisms and treatment. There is also evidence to show that the tumour cells can disseminate along the fibrin network strands (Hiramoto et al, 1960). Heparin reduces the incidence of metastases in some animal cancers, although it is ineffective on the primary tumour (Retik et al, 1962). Dicoumarin derivatives such as warfarin are also effective with some animal experimental cancer metastases and might also reduce the size of the primary tumour (Berkarda et al, 1974). Warfarin also has the ability to uncouple oxidative phosphorylation, which might be responsible for decreasing the mobility of malignant cells (Thornes et al, 1968).
As a result of these experimental studies and the observation of coagulation abnormalities in patients with cancer (Miller et al, 1967) several clinical studies have been undertaken. Thornes (1972) treated half his patients receiving therapy for various cancers with warfarin. He found that the anticoagulated group as a whole survived longer. There were a few patients with lung cancer in this study, but warfarin did not appear to alter the prognosis. In a non-randomised study anticoagulation with heparin in combination with cytotoxic drugs produced a remission in patients with carcinoma of the bronchus when they had failed to respond to radiotherapy and one or two courses of other chemotherapy (Elias and Brugarolas, 1972, Elias et al, 1975). Subsequent studies have not confirmed these hopeful results (Edlis et al, 1976; Rohwedder and Sagastome, 1977).

The present study differs from the above in several respects. All the patients suffered from small cell carcinoma of the bronchus and had not received previous radiotherapy or chemotherapy. The patients were randomly allocated to the anticoagulant or control groups and in addition to heparin and warfarin they were given intravenous dextran in view of its ability to decrease intravascular thrombosis (Kline et al, 1975).

\section{Methods}

Twenty-four patients with a histological diagnosis of small cell carcinoma of the bronchus were admitted to the study. Patients were not excluded because of minor haemoptysis, and they were assigned to either the anticoagulant or control 
treatment groups according to a table of random numbers.

Both groups received two induction courses of chemotherapy at three weekly intervals followed by maintenance drugs given three times weekly. Cyclohexylchlorethyl nitrosourea (CCNU) was given by mouth, but all the other cytotoxic drugs were given intravenously. The induction course consisted of $100 \mathrm{mg}$ CCNU (alternate courses only) on day one and $500 \mathrm{mg}$ cyclophosphamide, $1 \mathrm{mg}$ vincristine, and $15 \mathrm{mg}$ adriamycin, all on days two, three, and four. Methotrexate, $20 \mathrm{mg}$, was given on days two and four. The maintenance course given as an outpatient consisted of $100 \mathrm{mg}$ CCNU (alternate courses), $1 \mathrm{~g}$ cyclophosphamide, $1 \mathrm{mg}$ vincristine, and $10 \mathrm{mg}$ methotrexate.

The anticoagulant group were given the following drugs: 48 hours before each induction course of cytotoxic drugs they received a loading dose of 5000 IU heparin and then 20000 IU heparin a day for six days. During the first 24 hours of anticoagulants they also received 11 of dextran (Rheomacrodex). A loading dose of $25 \mathrm{mg}$ warfarin was given on the fourth day of heparin treatment and the dose adjusted to keep the prothrombin time at $20 \%$ of the control value. Warfarin was stopped before, and was reintroduced after, the second induction course but was not stopped for the maintenance courses of chemotherapy. On the day of the intravenous maintenance chemotherapy, each patient of the anticoagulant group also received $5000 \mathrm{IU}$ heparin contained in $500 \mathrm{ml}$ of dextran over a period of four hours.

The anticoagulant group consisted of ten men and two women while the control group had eight men and four women. All patients had at least stage $\mathrm{T} 3$ disease according to the criteria of the American Joint Committee for staging lung cancer (International Union against Cancer and American Joint Committee, 1973). Extrathoracic metastases were sought by clinical, radiological, and biochemical screening. Bone, liver, and brain isotope scanning was used when indicated. Bone marrow was not routinely aspirated.

\section{Results}

Extrathoracic metastases were present before treatment in ten out of 12 patients in the anticoagulant group and nine out of 12 of the control group. The median survival of the combined groups was $\mathbf{9 \cdot 2 8}$ months. All patients were dead 21 months after starting treatment.

The median survival time for the anticoagulated group was not significantly different from the
Comparison of survival after starting cytotoxic drugs in patients with small cell carcinoma of bronchus treated with or without anticoasulants

\begin{tabular}{llll}
\hline Group & $\begin{array}{l}\text { No of } \\
\text { patients }\end{array}$ & $\begin{array}{l}\text { Median } \\
\text { survival } \\
\text { (months) }\end{array}$ & Significance \\
\hline Anticoagulants & 12 & 8.85 & P $>0.05$ \\
Controls & 12 & 9.71 & P $>0.05$ \\
\hline
\end{tabular}

control group ( $\mathrm{P}>0.05$ ) (see table). Comparison of crude survival curves, after all patients had been at risk for 16 months, shows no differences between the two groups (see figure).

Haemoptysis increased in one patient after four months of treatment. His prothrombin time was less than $5 \%$ of the control value because of a misunderstanding about warfarin dosage. His haemoglobin did not drop significantly, and subsequent anticoagulant control was satisfactory. No haemorrhagic complications occurred in the other patients.

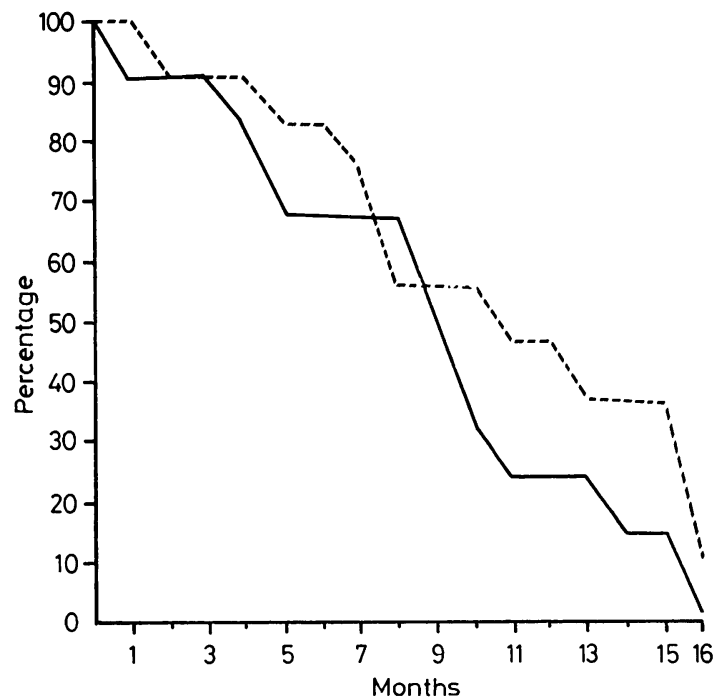

Survival curves (after all patients had been at risk for 16 months) for patients with small cell carcinoma after starting cytotoxic drugs with (- - ) or without (-- - - anticoagulants.

\section{Discussion}

The present report shows that anticoagulants, as used in this study, do not improve the prognosis of patients with small cell carcinoma of the bronchus. The median survival of patients treated for this disease with chemotherapy (Green et al, 1969; Eagan et al, 1974; Laing et al, 1975; Cohen 
et al, 1977) or chemotherapy combined with radiotherapy (Bitran et al, 1976; Johnson et al, 1976; Gilby et al, 1977) has ranged from three to 14 months. The median survival of the patients in the present study was over nine months, and thus the cytotoxic regimen gave a satisfactory baseline for investigation of the effects of anticoagulants. Since the small cell carcinoma is usually so responsive to chemotherapy in the initial stages of the disease (Broder et al, 1977) it may be that any possible contribution from anticoagulants is relatively small compared to the effect of the cytotoxic drugs. Metastases have already occurred at the time of diagnosis in most patients with this carcinoma (Vincent et al, 1976) and thus it may be too late for the anticoagulants to prevent the establishment of extravascular metastases in the manner suggested by Wood (1958). If anticoagulants are effective they should be able to prevent extension along the proposed fibrin network and hence stop the increase in size of the primary and secondary tumours (Hiramoto et al, 1960). This did not happen in the present study. The beneficial effects of warfarin, used alone in clinical studies, have become apparent after three months' treatment (Thornes, 1972). Most of the patients in the present study survived beyond this time and still failed to benefit.

Experimental results have shown not only that heparin fails to control some animal tumours, but that while apparently decreasing the numbers of pulmonary metastases it actually increases the systemic metastases (Hagmar, 1970). This effect may be due to alteration of the surface charge on the cancer cell by heparin so that it may produce some of its apparently beneficial results by a nonfibrin-related mechanism (Suemasu and Ishikawa, 1970). A simple redistribution of the metastatic growth to other organs may not be of much clinical benefit. Aspirin, which acts as a platelet inhibitor capable of preventing intra-arterial thrombosis, is ineffective in reducing metastases in animal experiments (Wood and Hilgard, 1972).

Immune stimulants such as BCG and Corynebacterium parvum may improve the prognosis in patients with early carcinoma of the lung when used in addition to other treatment. They have, however, been unsuccessful in patients with the small cell variety (Edwards and Whitwell, 1974; McKneally et al, 1976; Pines, 1976; Israël et al, 1977). In view of this difference in response between the varieties of carcinoma the results of the present study should not be used to generalise about the effect of anticoagulants on adenocarcinoma and squamous cell carcinoma. Patients need increased surveillance to control the heparin and warfarin dosage, and there is an undoubted risk of severe haemorrhage especially if anticoagulants are combined with platelet depressant drugs (Edlis et al, 1976). In view of this, future studies, if undertaken, should be properly randomised, and a close check must be kept on the dosage of drugs.

I thank Dr C F Campbell, Dr G Edelstyn, $\mathrm{Mr}$ H M Stevenson, and Mr T B Smiley for advice and criticism. Mr T Hassard, Department of Statistics, Queen's University, Belfast, advised in the analysis of results.

\section{References}

Berkarda, F B, D'Souza, J P, and Bakemeier, R F (1974). The effect of anticoagulants on tumour growth and spread in mice. Proceedings of the American Association of Cancer Research, 15, 99.

Bitran, J, Golomb, H M, and Desser, R K (1976). Combined therapy for small-cell carcinoma of the bronchus. Lancet, 1, 248-249.

Broder, L E, Cohen, M H, and Selawry, O S (1977). Treatment of bronchogenic carcinoma. II small cell. Cancer Treatment Review, 4, 219-260.

Cohen, M H, Ihde, D C, Fossieck, B E, Bunn, P A, Matthews, M J, Johnston, A V, and Minna, J D (1977). Intensive chemotherapy of small cell bronchogenic carcinoma. Proceedings of the American Association of Cancer Research, 18, 286.

Eagan, R T, Maurer, L H, Forcier, R J, Tulloh, M (1974). Small cell carcinoma of the lung. Staging, paraneoplastic syndromes, treatment and survival. Cancer, 33, 527-532.

Edlis, H E, Goudsmit, A, Brindley, C, and Niemetz, J (1976). Trial of heparin and cyclophosphamide (NSC-26271) in the treatment of lung cancer. Cancer Treatment Reports, 60, 575-578.

Edwards, R F, and Whitwell, F (1974). The use of BCG as an immunostimulant in the surgical treatment of carcinoma of the lung. Thorax, 29, 654-658.

Elias, E G, and Brugarolas, A (1972). The role of heparin in chemotherapy of solid tumors: preliminary clinical trial in carcinoma of the lung. Cancer Chemotherapy Reports, 56, pt I, 783-785.

Elias, E G, Shukla, S K, and Mink, I B (1975). Heparin and chemotherapy in the management of inoperable lung carcinoma. Cancer, 36, 129-136.

Gilby, E D, Bondy, P K, Morgan, R L, McElwain, T J (1977). Combination chemotherapy for small cell carcinoma of the lung. Cancer, 39, 1959-1966.

Green, R A, Humphrey, E, Close, H, and Patno, M E (1969). Alkylating agents in bronchogenic carcinoma. American Journal of Medicine, 46, 516525.

Hagmar, B (1970). Tumour growth and spontaneous metastasis spread in 2 syngenic systems. Acta Pathologica Microbiologica Scandinavica, 78, Sect A, 131-142. 
Hiramoto, R, Bernecky, J, Jurandowski, J, and Pressman, D (1960). Fibrin in human tumors. Cancer Research, 20, 592-593.

Hyde, L, Yee, J, Wilson, R, and Patno, M E (1965). Cell type and the natural history of lung cancer. Journal of the American Medical Association, 193, 52-54.

International Union against Cancer and American Joint Committee for cancer staging and end result reporting (1973). Clinical staging system for carcinoma of the lung. Geneva, IUAC.

Israël, L, Depierre, A, Choffel, C, Milleron, B, and Edelsten, R (1977). Immunochemotherapy in 34 cases of oat cell carcinoma of the lung with 19 complete responses. Cancer Treatment Reports, 61, 343-347.

Johnson, R E, Brereton, H D, and Kent, C H (1976). Small-cell carcinoma of the lung: Attempt to remedy causes of past therapeutic failure. Lancet, 2, 289-291.

Kline, A, Hughes, L E, Campbell, H, Williams, A, Zlosnick, J, and Leach, K G (1975). Dextran 70 in prophylaxis of thromboembolic disease after surgery: a clinically orientated randomized double-blind trial. British Medical Journal, 2, 109-112.

Laing, A H, Berry, R J, Newman, C R, and Smith, $P$ (1975). Treatment of small-cell carcinoma of the bronchus. Lancet, 1, 129-132.

McKneally, F M, Maver, C, and Kausel, H W (1976). Regional immunotherapy of lung cancer with intrapleural BCG. Lancet, 1, 377-379.

Miller, S P, Sanhez-Avalos, J, Stefanski, T, and Zuckerman, L (1967). Coagulation disorders in cancer-I Clinical and laboratory studies. Cancer, 20, 1452-1465.

Pines, A (1976). A five-year controlled study of BCG and radiotherapy for inoperable lung cancer. Lancet, 1, 380-381.
Retik, A B, Arons, M S, Ketcham, A S, and Mantel, $N$ (1962). The effect of Heparin on primary tumors and metastases. Journal of Surgical Research, 2, 49-53.

Rohwedder, J J, and Sagastome, E (1977). Heparin and polychemotherapy for the treatment of lung cancer. Cancer Treatment Reports, 61, 1399-1401.

Stanford, W, Spivey, C G, Larsen, G L, Alexander, J A, and Besich, W J (1976). Results of treatment of primary carcinoma of the lung. Journal of Thoracic and Cardiovascular Surgery, 72, 441-449.

Suemasu, I L, and Ishikawa, S (1970). Inhibitive effect of heparin and dextran sulfate on experimental pulmonary metastases. Gann, 61, 125-130.

Takita, H, Brugarolas, A, Marabella, P, and Vincent, R G (1973). Small cell carcinoma of the lung: Clinicopathological studies. Journal of Thoracic and Cardiovascular Surgery, 66, 472-477.

Thornes, R D (1972). Warfarin as maintenance therapy for cancer. Journal of the Irish College of Physicians and Surgeons, 2, 41-42.

Thornes, R D, Edlow, D W, and Wood, S jun (1968). Inhibition of locomotion of cancer cells in vivo by anticoagulant therapy. 1. Effects of sodium warfarin on V2 cancer cells, granulocytes, lymphocytes and macrophages in rabbits. The Johns Hopkins Medical Journal, 123, 305-316.

Vincent, R G, Takita, H, Lane, W W, Gutierrez, A C, and Pickren, J W (1976). Surgical therapy of lung cancer. Journal of Thoracic and Cardiovascular Surgery, 71, 581-591.

Wood, S jun (1958). Pathogenesis of metastasis formation in vivo in the rabbit ear chamber. Archives of Pathology, 66, 550-568.

Wood, S jun, and Hilgard, P (1972). Aspirin and tumour metastasis. Lancet, 2, 1416-1417.

Requests for reprints to: Dr C F Stanford, Royal Victoria Hospital, Grosvenor Road, Belfast BT12 6BA. 